\title{
The effects of a home-based exercise intervention on elderly patients with knee osteoarthritis: a quasi-experimental study
}

\author{
Hongbo Chen ${ }^{1}$, Xiaoyan Zheng ${ }^{2}$, Hongjie Huang ${ }^{3}$, Congying Liu', Qiaoqin Wan ${ }^{1}$ and Shaomei Shang ${ }^{\text {* }}$
}

\begin{abstract}
Background: Knee osteoarthritis (KOA) is common in elderly people, causes pain, loss of physical functioning, and disability. This was a two-arm, superiority, quasi-experimental trial. The aim of this study was to evaluate the effectiveness of a home-based exercise intervention (HBEI) to reduce KOA symptoms and improve the physical functioning of elderly patients.

Methods: A total of 171 elderly patients (60 years of age or older) with KOA were recruited from four community centers. Patients from two community centers were randomly assigned to the intervention group (IG) and the other two centers were randomly assigned to the control group (CG). Participants in the IG received a 12-week HBEl (including four 2-h sessions supervised by a physiotherapist and fortnightly telephone support) combined with health education, while patients in the CG only received health education. The participants and physiotherapists were aware of the group assignment and alternative treatment components, but the study's hypotheses were not disclosed to the participants. Pain intensity, joint stiffness, lower-limb muscle strength, balance, mobility, and quality of life were measured before and after the intervention by the same blinded assessor.
\end{abstract}

Results: A total of 171 patients (IG: $n=84, C G: n=87$ ) were enrolled. Data were obtained from 141 patients with an average age of 68 (range, 60-86 years) who completed the 12-week study (IG: $n=71, C G: n=70$ ). No significant group differences were found in any outcome measures at baseline. At week 12, the pretest/posttest changes 3significant between-group differences in decreases in pain intensity $(-1.60(\mathrm{Cl},-2.75$ to -0.58$))$ and stiffness $(-0.79(\mathrm{Cl},-1.37$ to -0.21$)$ ), with the IG exhibiting significantly larger improvements on both measures than the CG. The IG also showed significantly greater improvements on all the secondary outcomes than the CG did.

Conclusions: HBEl may be effective for relieving KOA symptoms, increasing the physical functioning, and improving quality of life in community-dwelling KOA elderly patients. A large randomized controlled trial with long-term followup is needed to confirm these findings.

Trial registration: Chinese Clinical Trails Registry number ChiCTR1800017026 (retrospectively registered). Registered 9 July 2018.

Keywords: Osteoarthritis, Aged, Exercise, Pain

\footnotetext{
*Correspondence: shangshaomei@126.com

${ }^{1}$ School of Nursing, Peking University, 38 Xueyuan Road, Haidian District,

Beijing 100191, China

Full list of author information is available at the end of the article
}

(c) The Author(s). 2019 Open Access This article is distributed under the terms of the Creative Commons Attribution 4.0 International License (http://creativecommons.org/licenses/by/4.0/), which permits unrestricted use, distribution, and reproduction in any medium, provided you give appropriate credit to the original author(s) and the source, provide a link to the Creative Commons license, and indicate if changes were made. The Creative Commons Public Domain Dedication waiver (http://creativecommons.org/publicdomain/zero/1.0/) applies to the data made available in this article, unless otherwise stated. 


\section{Background}

Knee osteoarthritis (KOA) is a common joint disease in elderly persons, which causes pain, loss of function and disability, and reduces quality of life [1], and affects approximately one-third of people over 60 years of age. The prevalence rate of $\mathrm{KOA}$ is estimated to be $42.8 \%$ in women and $21.5 \%$ in men in the elderly Chinese population [2]. The prevalence of symptomatic KOA in the United States is estimated to be $7-33 \%$, with the prevalence increasing with age; the knee is the most common site of symptomatic OA [3]. As there is no known cure for $\mathrm{OA}$, it is especially important to use non-pharmacological treatments to control its progression, relieve symptoms, and improve knee function and quality of life [4].

Exercise therapy, which is one of the most important non-pharmacological treatments, is a safe and low-cost method for treating KOA that has been shown to delay disease progression, relieve pain, and improve knee function $[5,6]$. Clinical guidelines recommend it as the primary non-pharmacologic treatment of KOA [7]. Common types of exercise for treating KOA include aerobic exercise (such as jogging, cycling, and swimming) and specific knee exercises, which include resistance exercise (mainly to strengthen muscles around the knee), proprioceptive exercise, and range of motion exercise [4, $6,8,9]$. Exercise interventions are usually performed under the supervision of physiotherapists in hospitals or physical therapy institutes, and require professional rehabilitation equipment [10-12]. However, one study reported that $44.2 \%$ of $\mathrm{KOA}$ patients withdrew from an exercise intervention conducted at a hospital due to time and economic pressures [13]. From the perspective of hospitals, moreover, providing long-term rehabilitation exercise for KOA patients is a drain on medical resources [4]. Therefore, it is imperative to transfer the location of rehabilitation exercise from inside the hospital to outside the hospital.

Rehabilitation physicians and researchers are increasingly recognizing the value of home-based exercise, which is a time-efficient and convenient treatment modality for patients with chronic diseases such as KOA [14]. It can performed by patients individually at home, unsupervised, and without professional equipment [15]. The goal of home-based and hospital-based exercise is the same; that is, to relieve pain and improve function by strengthening lower limb muscles, improving neuromuscular control, and range of joint motion in the affected knees $[15,16]$. The difference is that a home-exercise program needs to be easier to learn and safer to do than a hospital program, especially for elderly patients with KOA, because it is not supervised by a physiotherapist. Several current studies of home-exercise programs for patients with KOA have initially confirmed their feasibility and effectiveness [17-19], but the exercise programs used in each study were quite different and the number of studies is small. Moreover, no one has yet conducted home-exercise interventions in China.

This study aimed to evaluate the effectiveness of a program of home-based exercise intervention (HBEI) for older patients with KOA. Our hypotheses were that an HBEI would relieve patients' symptoms at week 12, including pain and stiffness, and improve their physical functioning and quality of life, compared to a health-education intervention.

\section{Methods \\ Study design}

This was a two-arm, superiority, quasi-experimental trial that was assessor-blinded and conducted in Beijing. The end-point for the analysis of the outcomes was 12 weeks after the baseline assessment. The study's Chinese Clinical Trails Registry number is ChiCTR1800017026.

\section{Setting and participants}

We recruited community-dwelling elderly patients with KOA from four community centers in Beijing via print and social-media advertisements. The study was conducted at the community- health centers of these four communities. After community nurses recruited elderly individuals from the community centers who had been diagnosed with $\mathrm{KOA}$, the doctors screened them, according to the inclusion and exclusion criteria, and determined who could participate in the study. The inclusion criteria were: being 60 years of age or older; experiencing knee pain on most days of the past month; average knee pain in the last week between 3 and 7 on an 11-point numeric rating scale (NRS); and having intact cognitive functioning, as indicated by a Short Portable Mental Status Questionnaire score of 8-10 (The range of score for this questionnaire is 0-10) [20]. The exclusion criteria were: having had joint replacement surgery or arthroscopic surgery on the affected side of the knee; other surgery on lower limbs within the past 6 months; severe deformity of lower limbs (e.g., knee varus or knee valgus); having health problems that can easily induce adverse events during home exercise, such as uncontrolled high blood pressure, a myocardial infarction, cerebral infarction, unstable angina, arrhythmia, severe vision problems, or neurological dysfunction. Then, the participants gave their informed consent and completed the baseline assessments.

\section{Randomization and blinding}

We performed randomization on a community level rather than an individual level to avoid contamination effects among participants within a community. An independent researcher, who was not involved in the treatment or assessments, used the random number function of Excel to generate randomization sequences. 
Table 1 Details of home-based exercises

\begin{tabular}{|c|c|}
\hline Exercises & Details \\
\hline $\begin{array}{l}\text { Isometric contractions of the } \\
\text { quadriceps }\end{array}$ & $\begin{array}{l}\text { 1. Sitting or lying down, legs relaxing; } \\
\text { 2. Tight the thigh muscles on one side with maximum strength, keep it for } 5 \mathrm{~s} \text {, and relax for } 2 \mathrm{~s} \text {. Repeat } 10 \text { times for } \\
1 \text { group and practice } 10 \text { groups in succession; } \\
\text { 3. Relax this leg and repeat the above action on the other side; } \\
\text { 4. Exercise alternately } 3 \text { to } 5 \text { times with both legs. }\end{array}$ \\
\hline Supine straight-leg lifts & $\begin{array}{l}\text { 1. Lie on the back, stretch knees; } \\
\text { 2. One leg is flexed to support the bed surface, the other leg is raised to the heel, about } 20 \mathrm{~cm} \text { away from the bed, } \\
\text { held for } 5 \text { seconds, put down for } 5 \mathrm{~s} \text {, repeat } 10 \text { times; } \\
\text { 3. Relax this leg and repeat the above action on the other side; } \\
\text { 4. Exercise alternately } 3 \text { to } 5 \text { times with both legs. }\end{array}$ \\
\hline Leg lifts in the prone position & $\begin{array}{l}\text { 1. Lie face down, stretch knees; } \\
\text { 2. Lift one leg back to the toe, about } 20 \mathrm{~cm} \text { away from the bed, held for } 5 \mathrm{~s} \text {, put down for } 5 \mathrm{~s} \text {, repeat } 10 \text { times; } \\
\text { 3. Relax this leg and repeat the above action on the other side; } \\
\text { 4. Exercise alternately } 3 \text { to } 5 \text { times with both legs. }\end{array}$ \\
\hline Passive knee flexion & $\begin{array}{l}\text { 1. Sit on the bed; } \\
\text { 2. Hold your hands on one side of the ankle, slowly and forcefully hold the leg to the chest to maximize knee flexion, } \\
\text { keep60 s; } \\
\text { 3. Relax this leg and repeat the above action on the other side; } \\
\text { 4. Exercise alternately } 2 \text { to } 3 \text { times with both legs. }\end{array}$ \\
\hline Passive knee extension & $\begin{array}{l}\text { 1. Sit on the bed; } \\
\text { 2. Put one side of the foot pad } 8 \sim 10 \mathrm{~cm} \text { high; } \\
\text { 3. Apply light weight to the raised knee joint or apply proper pressure by hand for } 60 \mathrm{~s} \text {; } \\
\text { 4. Relax this leg and repeat the above action on the other side; } \\
\text { 5. Exercise alternately } 2 \text { to } 3 \text { times with both legs. }\end{array}$ \\
\hline Resistance knee extension & $\begin{array}{l}\text { 1. Sit on the chair or at the bed, tie a } 1 \mathrm{~kg} \text { sandbag to the ankle, keep the upper body straight; } \\
\text { 2. Do not move the thighs, lift your calves until the knees are fully extended, hold for } 5 \mathrm{~s} \text {, rest your legs for } 5 \text { seconds, } \\
\text { repeat } 10 \text { times; } \\
\text { 3. Relax this leg and repeat the above action on the other side; } \\
\text { 4. Exercise alternately } 2 \text { to } 3 \text { times with both legs. }\end{array}$ \\
\hline Resistance knee flexion & $\begin{array}{l}\text { 1. Standing up, tie a } 1 \mathrm{~kg} \text { weight sandbag to the ankle joint, and support the upper edge of the chair; } \\
\text { 2. Stand on one leg and pull the calf back to the other leg, flexing the knee as much as possible while keeping the thigh } \\
\text { perpendicular to the ground. Hold for } 5 \mathrm{~s} \text {, put your legs down for } 5 \mathrm{~s} \text {, repeat } 10 \text { times } \\
\text { 3. Relax this leg and repeat the above action on the other side; } \\
\text { 4. Exercise alternately } 2 \text { to } 3 \text { times with both legs. }\end{array}$ \\
\hline $\begin{array}{l}\text { Shifting the center of gravity } \\
\text { (left and right) }\end{array}$ & $\begin{array}{l}\text { 1. Stand up and support a table with a height of } 70 \sim 80 \mathrm{~cm} \text { and open the feet; } \\
\text { 2. Keep your knees upright, slowly move the center of gravity to the left, and gradually lower your right heel; } \\
\text { 3. Keep your knees upright, slowly move the center of gravity to the right, and gradually lower your left heel; } \\
\text { 4. Repeat the above action for } 3 \text { min. }\end{array}$ \\
\hline $\begin{array}{l}\text { Shifting the center of gravity } \\
\text { (forwards and backwards) }\end{array}$ & $\begin{array}{l}\text { 1. Stand up and support a table with a height of } 70 \sim 80 \mathrm{~cm} \text { and take one step forward on one side; } \\
\text { 2. Keep the knees upright, slowly move the center of gravity forward, and the heel of the hind foot gradually leaves } \\
\text { the ground; } \\
\text { 3. Keep the knees upright, slowly move the center of gravity backwards, and the forefoot gradually leaves the ground; } \\
\text { 4. Repeat the above action for } 3 \text { min. }\end{array}$ \\
\hline
\end{tabular}

The random numbers were placed in opaque envelopes, which were subsequently opened by study staff, who knew the community allocation, in sequence after community recruitment. Patients from two community centers were randomly assigned to the intervention group and patients from the other two centers were randomly assigned to the control group. Participants and physiotherapists were unblinded to group assignment and were aware of the alternative treatment components, but the study's hypotheses were not disclosed to the participants. The assessor and statistician were blinded to participant allocation.

\section{Intervention condition}

Participants in the intervention group attended four 2-h sessions conducted by physiotherapists over 12 weeks (weeks 0, 2, 4, and 6). Each session, which was conducted in groups of 6-12 patients, included an hour for health education and an hour for exercise. Participants also performed home-based practice during the study. They were instructed to complete a home-exercise diary in order to remind them to do their home exercises. Research assistants telephoned participants at weeks $1,3,5,7$, and 9 to discuss their progress and adherence to the home program, and encouraged them to adhere to the exercise program.

Health education involved four modules delivered by physiotherapists that covered the concepts of clinical manifestations, risk factors, clinical examination and diagnosis, treatment and nursing care for KOA, the benefits of exercise, the home environment, and information about daily care for KOA. Each participant in the intervention 
group received a paper version of material titled "Health Knowledge and Home Exercise Guide for KOA" in order to consolidate their memory of health knowledge and exercise programs (for details, see the Additional file 1).

The exercise program, which was created based on a literature review, clinical practice, and consultation with experts during our previous studies, aimed to increase lower-limb muscle strength and balance, relieve pain, and reduce knee stiffness. Each exercise session involved isometric contractions of the quadriceps, supine straight-leg lifts, leg lifts in the prone position, resistance knee extension, resistance knee flexion, passive knee flexion, passive knee extension, and shifting the center of gravity (left and right/before and after). Nine home-based exercises for individuals with KOA (Table 1) were recommended with an exercise prescription of 3040 min per day at least 3 days per week. Not all participants performed the same exercise program; the physiotherapists developed personalized plans for the patients based on their physical functioning and knee symptoms.

\section{Control condition}

Participants in the control group received the same number of health-education sessions, telephone follow-ups, and the same paper materials as the participants in the intervention group, but their health education and paper materials did not include exercise-related information. Their health face-to-face education sessions were also conducted in groups of 6-12 patients. During the telephone follow-up, the research assistants asked about the patient's condition, answered the patient's questions, and told the patient to protect the knee in accordance with the health-education content about daily care. The control group did not receive any guidance about home-based exercise.

\section{Training of physiotherapists, research assistants, and the assessor}

The physiotherapists, who worked in a general hospital and had $\geq 5$ years of musculoskeletal clinical experience, underwent at least $4 \mathrm{~h}$ of training about programs of HBEI. The research assistants and the assessor were medical undergraduates who received at least $8 \mathrm{~h}$ of training regarding their respective tasks. All the training sessions in our study were conducted by the researchers.

\section{Outcome assessment}

The participants were assessed by the same blinded assessor at baseline (pretest) and week 12 (posttest). Personal information was collected using a demographic questionnaire developed for this study, which included questions about age, gender, height and weight (body mass index [BMI]), ethnic group, marital status, educational level, occupation before retirement, average monthly household income, residence, living arrangement, disease duration, comorbidities, and history of falls within the past year. All the questionnaire used in our study were administered on paper.

\section{Primary outcome measures}

The primary outcomes of the study were pain intensity and joint stiffness related to KOA. Pain intensity and joint stiffness related to KOA were measured by the Western Ontario and McMaster Universities Osteoarthritis Index (WOMAC) [21]. It includes 7 items on pain and joint stiffness that are rated on a 0-4 Likert scale. Higher scores reflect greater pain and stiffness. The internal reliability of the Chinese version of the WOMAC, as measured by Cronbach's alpha, is $0.67-0.82$ for its three subscales and its test-retest reliability, based on the intraclass correlation coefficient (ICC), is $0.82-0.88$ for its three subscales [22].

\section{Secondary outcome measures}

The secondary outcomes included the muscle strength of the lower limbs, balance, walking ability, and quality of life. The muscle strength of the lower limbs was measured by the Five-Times-Sit-to-Stand Test (FTSST), in which participants rise from a chair and return to a seated position as quickly as possible with their arms folded across their chests. The time to complete five repetitions was recorded for two separate trials, with a 1 min rest between each trial. The mean of the two trials was computed and used in the analysis [23].

Balance was measured using the Timed Up and Go test (TUG). The TUG assesses the length of time it takes participants to get up from a standard height chair, walk $3 \mathrm{~m}$, turn and return to the chair, and sit down again [24]. Walking ability was measured using the Six-Minute Walk Test (6MWT). This test measures the distance an individual is able to walk in $6 \mathrm{~min}$ on a $30 \mathrm{~m}$, hard, flat, indoor surface. Standardized verbal encouragement is allowed to be provided at $1 \mathrm{~min}$ intervals and during rest [25].

Quality of life was measured by the Arthritis Impact Measurement Scales 2 - Short Form (AIMS2-SF), which is a self-assessment scale specifically for arthritis patients [26]. It consists of 26 items measured on a 5-point Likert scale. As we were assessing the quality of life of elderly patients with KOA in our study, we deleted two items about the hand and arm and two items about work, resulting in a 19-item scale that included seven items from the body dimension, three items from the symptom dimension, five items from the emotional dimension, and four items from the society dimension. The range of possible scores was 19-95. Internal consistency, as measured by Cronbach's alpha, was $0.65-0.83$ [27].

We designed a questionnaire to assess the patient's exercise compliance. The questionnaire contained four 
Table 2 The demographic characteristics of the recruited sample at baseline

\begin{tabular}{|c|c|c|c|c|c|c|c|}
\hline \multirow[t]{2}{*}{ Characteristic } & \multicolumn{2}{|c|}{ Total $(n=141)$} & \multicolumn{2}{|c|}{ Intervention $(n=71)$} & \multicolumn{2}{|c|}{ Control $(n=70)$} & \multirow[t]{2}{*}{$P$-value } \\
\hline & $N$ & (\%) & $n$ & $(\%)$ & $n$ & (\%) & \\
\hline Age - Mean (SD), y & 68.9 & $(7.35)$ & 68.9 & $(7.78)$ & 68.8 & $(6.96)$ & 0.963 \\
\hline \multicolumn{8}{|l|}{ Gender $^{a}$} \\
\hline Male & 22 & $(15.6)$ & 12 & $(16.9)$ & 10 & $(14.3)$ & 0.669 \\
\hline Female & 119 & $(84.4)$ & 59 & $(83.1)$ & 60 & $(85.7)$ & \\
\hline Body mass index - Mean (SD), kg/m² & 25.2 & $(3.48)$ & 25.0 & $(3.45)$ & 25.4 & $(3.51)$ & 0.565 \\
\hline Symptom duration - Mean (SD), y & 6.4 & $(8.52)$ & 6.7 & $(9.39)$ & 6.0 & (7.60) & 0.664 \\
\hline Level of education ${ }^{a}$ & & & & & & & 0.524 \\
\hline Primary school or less & 22 & $(15.6)$ & 12 & $(16.9)$ & 10 & $(14.3)$ & \\
\hline Junior high school & 48 & $(34.0)$ & 25 & $(35.2)$ & 23 & (32.9) & \\
\hline High school & 31 & $(22.0)$ & 12 & $(16.9)$ & 19 & $(27.1)$ & \\
\hline College graduate and above & 40 & $(28.4)$ & 22 & $(31.0)$ & 18 & $(25.7)$ & \\
\hline Marital status ${ }^{a}$ & & & & & & & 0.669 \\
\hline Single & 22 & $(15.6)$ & 12 & $(16.9)$ & 10 & $(14.3)$ & \\
\hline Married & 119 & $(84.4)$ & 59 & $(83.1)$ & 60 & $(85.7)$ & \\
\hline Number of affected knees ${ }^{a}$ & & & & & & & 0.207 \\
\hline One & 63 & $(44.7)$ & 28 & $(39.4)$ & 35 & $(50.0)$ & \\
\hline Two & 78 & $(55.3)$ & 43 & $(60.6)$ & 35 & $(50.0)$ & \\
\hline Uses a walker ${ }^{\mathrm{a}}$ & & & & & & & 0.637 \\
\hline Yes & 5 & $(3.5)$ & 2 & $(2.8)$ & 3 & $(4.3)$ & \\
\hline No & 136 & $(96.5)$ & 69 & $(97.2)$ & 67 & $(95.7)$ & \\
\hline \multicolumn{8}{|l|}{ Comorbid conditions $^{a}$} \\
\hline Hypertension & & & & & & & 0.553 \\
\hline Yes & 68 & $(48.2)$ & 36 & $(50.7)$ & 32 & $(45.7)$ & \\
\hline No & 73 & $(51.8)$ & 35 & $(49.3)$ & 38 & (54.3) & \\
\hline Diabetes & & & & & & & 0.560 \\
\hline Yes & 29 & (20.6) & 16 & $(22.5)$ & 13 & (18.6) & \\
\hline No & 112 & $(79.4)$ & 55 & $(77.5)$ & 57 & $(81.4)$ & \\
\hline Coronary heart disease & & & & & & & 0.743 \\
\hline Yes & 38 & $(27.0)$ & 20 & $(28.2)$ & 18 & $(25.7)$ & \\
\hline No & 103 & $(73.0)$ & 51 & $(71.8)$ & 52 & (74.3) & \\
\hline Osteoporosis & & & & & & & 0.105 \\
\hline Yes & 21 & $(14.9)$ & 14 & $(19.7)$ & 7 & $(10.0)$ & \\
\hline No & 120 & $(85.1)$ & 57 & $(80.3)$ & 63 & $(90.0)$ & \\
\hline \multicolumn{8}{|l|}{ Current drug use } \\
\hline Analgesics & & & & & & & 0.654 \\
\hline Yes & 32 & $(22.7)$ & 15 & $(21.1)$ & 17 & (24.3) & \\
\hline No & 109 & $(77.3)$ & 56 & (78.9) & 53 & $(75.7)$ & \\
\hline Cartilage protection drugs & & & & & & & 0.067 \\
\hline Yes & 29 & $(20.6)$ & 19 & $(26.8)$ & 10 & $(14.3)$ & \\
\hline No & 112 & $(79.4)$ & 52 & $(73.2)$ & 60 & $(85.7)$ & \\
\hline
\end{tabular}

${ }^{a}$ Chi-square or Fisher's Exact tests were used

${ }^{\mathrm{b}}$ Independent samples $t$-test was used 


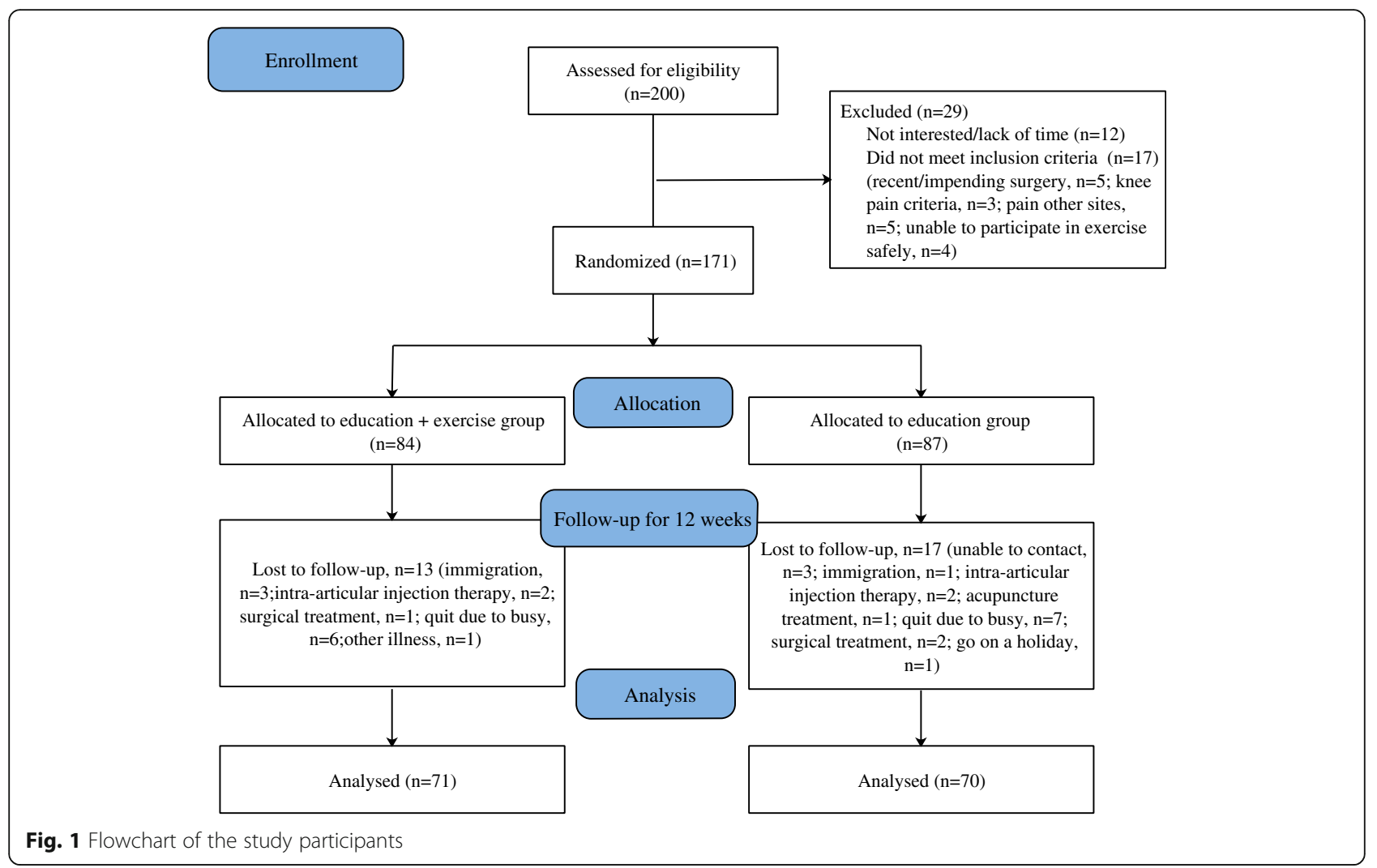

items, including "exercise at least 3 times per week," "reach the desired amount of exercise each time," "guarantee the quality of each action," and "total home-exercise time is $30-40$ minutes each time." The items were rated on a 4-point scale, in which $1=$ "cannot do it at all" and $4=$ "can do it completely." Exercise compliance rate $=$ actual score/theoretical maximum score $\times 100 \%$. The patients were divided into three categories, based on their exercise compliance rate: high $(\geq 75 \%)$, medium $(75-50 \%)$, and low $(\leq 50 \%)$.

\section{Sample size}

The primary outcome was the change in the pain and joint stiffness dimension of the WOMAC between the experimental group and control group at the end of the treatment (12 weeks). Assuming a mean difference (and SD) between the groups based on the results of relevant research on exercise interventions [28], power analysis was conducted with $\alpha=0.05, \beta=0.90$, and intervention and control groups of equal sample size. Power Analysis and Sample Size (PASS 2008) software estimated that 69 patients were needed per group. Given a projected dropout rate of $15 \%$, we aimed to include 80 patients per group.

\section{Statistical analysis}

The data were analyzed using SPSS version 23.0 (IBM Corporation, Armonk, NY, USA). Descriptive statistics, including means and standard deviations (SDs), or medians and the interquartile range (IQR), as well as frequencies and percentages, were used to summarize the demographic and disease characteristics and scores on the FTSST, TUG, 6MWT, and WOMAC. Inferential statistics were used to analyze the data, including the independent $t$-test, Mann-Whitney $\mathrm{U}$ test and the general linear model (GLM). As the randomization unit was the communities rather than the study participants, the GLM treated group as a fixed factor and community as a random factor, with baseline scores as covariates.

\section{Results}

The descriptive characteristics of the participants are shown in Table 2. Most of the participants were women (84.4\%), married (84.4\%), had a junior high-school education (34.0\%), had two affected knees (55.3\%), and did not use a walker $(96.5 \%)$. The most common comorbid condition was hypertension (48.2\%), followed by diabetes (20.6\%), coronary heart disease (27.0\%), and osteoporosis (14.9\%). About one-third of the participants used analgesics $(32 \%)$ and cartilage-protective drugs (29\%) to relieve pain and other symptoms of KOA. Figure 1 shows a flowchart of numbers of patients at different points in the study. Of the 200 patients from four community centers, 29 (14.5\%) were ineligible or did not wish to participate, and 171 were enrolled. The treatment groups were 
similar at baseline with respect to demographics, clinical characteristics, and amount of therapy (Table 2). Thirty of the 171 patients were lost to follow-up (17.5\%). The patients who were lost to follow-up had similar baseline characteristics and outcomes as the patients who remained in the study (data not shown). The overall rate of attending the exercise-class sessions was $82.5 \%$. At 12 weeks, there were 51 participants (71.8\%) with good compliance (compliance rate $\geq 75 \%$ ), 16 (22.6\%) with moderate compliance(compliance rate $50-75 \%$ ), and four (5.6\%) with poor compliance (compliance rate $\leq 50 \%$ ).

\section{Pain intensity and joint stiffness}

No significant group differences were found in pain intensity or joint stiffness at baseline. The baseline (pretest) average pain score on the WOMAC was 7.34 (SD 3.36) in the intervention group and 7.19 (SD 4.48) in the control group (see Table 3). The median baseline stiffness score on the WOMAC was 2 (IQR 0,3) in the intervention group and 2 (IQR 1,4) the control group. At week 12 (the posttest), however, the average pain score of the intervention and control groups had decreased to 4.28 (SD 3.30) and 5.73 (SD 3.54), respectively; the median stiffness score was 1 (IQR 0,3) in the intervention group, but it was still 2 (IQR 1,4) in the control group. The GLM showed that the pretest/posttest changes reflected significant between-group differences in decreases in pain intensity $(-1.60(\mathrm{CI},-2.75$ to -0.58$))$ and stiffness $(-0.79(\mathrm{CI},-$ 1.37 to -0.21$)$ ), with the intervention group exhibiting significantly larger improvements in outcomes on both measures than the control group.

\section{Muscle strength, balance, and mobility}

Table 3 shows the results for muscle strength, balance, and mobility. There were no significant group differences in any of the outcomes at baseline. The average level of muscle strength (IG: $14.22 \mathrm{~s}$ vs. $12.13 \mathrm{~s}$; CG: $14.49 \mathrm{~s}$ vs. $14.13 \mathrm{~s}$ ) and balance (IG: $13.30 \mathrm{~s}$ vs. $11.73 \mathrm{~s}$; CG: $13.02 \mathrm{~s}$ vs. $12.60 \mathrm{~s})$ increased by week 12 in both the intervention and control groups, whereas mobility (IG: $408.45 \mathrm{~m}$ vs. 442.39 m; CG: $422.86 \mathrm{~m}$ vs. $417.57 \mathrm{~m}$ ) increased in the intervention group, but decreased in the control group. The GLM, which controlled for baseline scores and the community factor, revealed the intervention group reported significantly better muscle strength (parameter estimate, $-2.82 \mathrm{~s}$ [CI, -3.70 to $-1.94 \mathrm{~s}]$ in the FTSST), balance (parameter estimate, $-1.37 \mathrm{~s}$ [CI, -1.96 to $-0.78 \mathrm{~s}$ ] in the TUG), and mobility (parameter estimate, $29.81 \mathrm{~m}$ [CI, 13.11 to 46.51 $\mathrm{m}]$ in the 6MWT) than the control group at week 12 .

\section{Quality of life}

Table 3 presents the total score and the scores for each dimension of quality of life, as measured by the AIMS2-SF. There were no group differences at baseline. The quality of life of both the intervention and control groups increased by week 12 , as measured by their total scores (IG: 75.06 vs. 82.00 ; CG: 76.57 vs. 77.90 ) and

Table 3 Outcome measures over time by group ${ }^{b}$

\begin{tabular}{|c|c|c|c|c|c|c|c|c|c|}
\hline & \multicolumn{2}{|c|}{ Intervention $(n=71)$} & \multicolumn{2}{|l|}{ Control $(n=70)$} & \multirow[t]{2}{*}{$P$-value $\neq$} & \multirow[t]{2}{*}{$\mathrm{F}$} & \multirow[t]{2}{*}{$P$-valuet } & \multirow{2}{*}{$\begin{array}{l}\text { Parameter } \\
\text { estimate } \\
\text { of GLM }\end{array}$} & \multirow{2}{*}{$\begin{array}{l}95 \% \mathrm{Cl} \text { of } \\
\text { parameter } \\
\text { estimate } \\
\text { of GLM }\end{array}$} \\
\hline & $\begin{array}{l}\text { Baseline } \\
(\text { mean } \pm S D)\end{array}$ & $\begin{array}{l}12 \text { weeks } \\
(\text { mean } \pm S D)\end{array}$ & $\begin{array}{l}\text { Baseline } \\
(\text { mean } \pm S D)\end{array}$ & $\begin{array}{l}12 \text { weeks } \\
(\text { mean } \pm S D)\end{array}$ & & & & & \\
\hline \multicolumn{10}{|l|}{ Primary outcome } \\
\hline WOMAC pain & $7.34 \pm 3.36$ & $4.28 \pm 3.30$ & $7.19 \pm 4.48$ & $5.73 \pm 3.54$ & 0.683 & 7.575 & $0.007^{*}$ & -1.60 & $-2.75,-0.58$ \\
\hline WOMAC stiffness ${ }^{a}$ & $2(0,3)$ & $1(0,3)$ & $2(1,4)$ & $2(1,4)$ & 0.428 & 7.215 & $0.008^{*}$ & -0.79 & $-1.37,-0.21$ \\
\hline \multicolumn{10}{|l|}{ Secondary outcomes } \\
\hline FTSST, S & $14.22 \pm 3.10$ & $12.13 \pm 2.93$ & $14.49 \pm 4.10$ & $14.13 \pm 4.13$ & 0.669 & 40.272 & $<0.001^{*}$ & -2.82 & $-3.70,-1.94$ \\
\hline TUG, s & $13.30 \pm 3.14$ & $11.73 \pm 1.97$ & $13.02 \pm 3.27$ & $12.60 \pm 2.81$ & 0.611 & 21.178 & $<0.001^{*}$ & -1.37 & $-1.96,-0.78$ \\
\hline $6 \mathrm{MWT}, \mathrm{m}$ & $408.45 \pm 60.54$ & $442.39 \pm 49.70$ & $422.86 \pm 49.29$ & $417.57 \pm 53.04$ & 0.124 & 12.457 & $0.001^{*}$ & 29.81 & $13.11,46.51$ \\
\hline AIMS2-SF total & $75.06 \pm 10.00$ & $82.00 \pm 9.96$ & $76.57 \pm 10.62$ & $77.90 \pm 9.52$ & 0.433 & 13.263 & $<0.001^{*}$ & 5.08 & $2.32,7.84$ \\
\hline AIMS2-SF-body & $27.04 \pm 4.50$ & $29.54 \pm 3.82$ & $27.94 \pm 4.77$ & $28.43 \pm 4.29$ & 0.174 & 8.459 & $0.004^{*}$ & 1.65 & $0.53,2.77$ \\
\hline AIMS2-SF-symptoms & $10.75 \pm 2.41$ & $12.62 \pm 1.85$ & $10.89 \pm 2.11$ & $11.34 \pm 1.78$ & 0.998 & 11.548 & $0.001^{*}$ & 1.30 & $0.54,2.05$ \\
\hline AIMS2-SF- emotional $^{a}$ & $21(20,24)$ & $25(20,25)$ & $22(20,24)$ & $22(19.75,24)$ & 0.486 & 5.640 & $0.019^{*}$ & 1.11 & $0.19,2.03$ \\
\hline AIMS2-SF- society ${ }^{a}$ & $16(15,18)$ & $18(15.20)$ & $17(14,20)$ & $17(14.75,20)$ & 0.316 & 5.403 & $0.022^{*}$ & 1.11 & $0.17,2.05$ \\
\hline
\end{tabular}

₹ Independent $t$-test or Mann-Whitney $U$ Test was used (week 0 intergroup comparison)

† The general linear model was used to analyze differences between the intervention and control groups; community was a random factor; baseline scores were covariates; and the control group was the reference

${ }^{a}$ Median (Interquartile Range)

${ }^{\mathrm{b}}$ FTSST Five-times-sit-to-stand test, the unit of this outcome measure is seconds, TUG Timed up and go test, the unit of this outcome measure is seconds, $6 M W T$ The six-minute walk test, the unit of this outcome measure is meters, WOMAC Western Ontario and McMaster Universities osteoarthritis index, pain (0-20), stiffness (0-8), AIMS2-SF Arthritis impact measurement scales 2 - short form, body (7-35), symptom (3-15), emotional (5-25), society (4-20), total (19-95), Cl Confidence interval, SD Standard deviation, GLM General linear model. $p<0.05$ was considered statistically significant 
body-dimension (IG: 27.04 vs. 29.54; CG: 27.94 vs. 28.43) and symptom-dimension scores (IG: 10.75 vs. 12.62; CG:10.89 vs. 11.34). However, the GLM showed the intervention group had a better quality of life than the control group did at week 12, based on statistically significant between-group differences in their posttest scores, including their total score (parameter estimate, 5.08 [CI, 2.32 to 7.84$]$ ), body score (parameter estimate, 1.65 [CI, 0.53 to 2.77$]$ ), symptoms score (parameter estimate, 1.30 [CI, 0.54 to 2.050], emotional score (parameter estimate, 1.11 [CI, 0.19 to 2.03], and society score (parameter estimate, 1.11 [CI, 0.17 to 2.05$]$ ).

\section{Discussion}

This 12-week quasi-experimental study showed that an HBEI and health education significantly reduced symptoms of KOA (i.e., pain intensity and joint stiffness) in elderly patients, and improved their physical functioning (i.e., lower-limb muscle strength, balance, and mobility) and quality of life, compared to an intervention that only involved health education. Furthermore, the overall rate of attending the exercise-class sessions was 82.5 , and $71.8 \%$ of the patients in exercise group showed good compliance (compliance rate $\geq 75 \%$ ) with the exercise program.

The control group also showed improvement on many of the outcomes; we attribute this to the effect of health education and the statistical phenomenon of regression toward the mean. The knowledge about proper knee care provided by the health-education program would be expected to help patients to take appropriate measures to relieve their knee pain, which would eventually improve their symptoms. Regression toward the mean is a statistical phenomenon that occurs when repeated measurements are made on the same subjects or units of observation [29]. Even if the true mean does not change, the result of the repeated measurements may increase or decrease due to regression toward the mean. Nevertheless, we found significant group differences in symptom and functional outcomes by week 12 of the study, in which the intervention group showed significantly greater improvement on all of the outcomes, compared to the control group. Therefore, the HBEI may be effective.

This study used the WOMAC index to evaluate the effectiveness of home-based exercise to improve the symptoms of patients with KOA. The results showed that patients who received the exercise intervention combined with health education reported significantly less pain and joint stiffness than patients who only received health education. Spanish scholars Escalantea et al. [30] conducted a meta-analysis of 33 studies on the effect of exercise on knee pain that was evaluated by the pain subscale of the WOMAC. The results showed that exercise reduced knee pain, which is usually the most common and the earliest symptom of patients with KOA.
Initial KOA pain is mild or moderate and intermittent, and it is reduced by resting. Late manifestations of KOA pain are persistent or nocturnal, and severely affect the patient's daily life [31]. Because of a lack of proper knowledge about health, many elderly people with KOA take inappropriate medications or exercise treatments, which eventually lead to increased pain. Therefore, it is vital to provide effective health education and exercise guidance for elderly patients with KOA. HBEI in our study could have relieved knee pain in patients with KOA for the following reasons [32, 33]: (1) HBEI caused the knee cartilage to be squeezed frequently and the joint fluid to continuously enter and exit the matrix, which promoted cartilage growth and joint repair, and reduced knee pain; (2) Proper home exercise promoted the metabolism of the knee's blood circulation and inflammatory factors, which in turn, reduced inflammation and decreased pain; and (3) Exercise increased muscle strength in the lower extremities and improved the maximum load and stability of the knee, which reduced wear of the articular cartilage and relieved knee pain.

Patients with KOA suffer from joint stiffness due to pain, damage to the cartilage and joint surface, joint effusion, and synovial adhesions. The results of this study regarding the effect of exercise to reduce stiffness in patient are consistent with those of previous studies [13, 34]. Range of joint-motion training combined with lower-limb muscle strength training promotes the range of motion, cartilage metabolism, and the absorption of joint effusion, and removes inflammatory products, which prevents synovial adhesions and the formation of vasospasm, thereby reducing joint stiffness [32].

Compared to healthy elderly people of similar age, patients with KOA generally have poor physical functioning, which is manifested by insufficient lower-limb muscle strength, poor balance, and decreased mobility. Previous studies have shown that there is a 10 to $60 \%$ decrease in the strength of the quadriceps muscle in patients with KOA [35], and that the thickness of the quadriceps tendons decreases significantly as the disease progresses [36]. Decreased knee-muscle strength can lead to insufficient joint stability, which leads to an abnormal distribution of stress in the patellofemoral joint and promotes its deterioration. Rasch et al. [37] believes that the muscle weakness caused by osteoarthritis is related to decreased joint function and increased pain, and that quadriceps training can increase muscle strength and relieve joint pain. Canadian researchers Peeler et al. [38] found that the strength of the quadriceps and hamstring muscles of KOA patients living in the community increased significantly after 12 weeks of training. This is consistent with our findings.

Decreased balance and mobility are the main cause of falls in elderly people [39]. Studies have shown that the 
risk of falls in KOA patients is $30 \%$ higher than that of non-KOA patients of the same age [40]. Falls are serious adverse events for elderly people, which may cause disability or even death. According to Arnold's research [41], an exercise intervention can improve balance and mobility, and prevent falls by elderly patients with KOA. Exercise can increase the muscle strength of the lower limbs to stabilize the knees and coordinate gait [42]. In addition, an increase in neuromuscular control and enhanced swing-knee height when walking can result in a reduced risk of falls [43].

With the transformation of modern medical models, quality of life has been widely used as a comprehensive indicator of health status in some medical fields, including chronic disease. Evaluating the quality of life of KOA patients makes it is possible to understand not only the physical discomfort caused by the disease, but to understand its psychological and social effects on patients. A 2012 study by French researchers Rat et al. [44], which measured the quality of life of 813 patients with arthritis using the AIMS2-SF, found their quality of life significantly decreased, especially on the three dimensions of body, symptoms, and emotion. A 2017 study by Taiwanese researchers Huang et al. [45] showed that the quality of life of KOA patients was negatively correlated with pain intensity and positively correlated with physical functioning. Given these results, the results of a study by the Turkish researchers Aglamis et al. [28] are particularly valuable because they showed that a 12 -week multicomponent program of exercise significantly improved the quality of life of patients with KOA. In our study, the exercise intervention decreased pain intensity and joint stiffness in patients, and increased their physical functioning, including lower-limb muscle strength, balance, and mobility. Therefore, the improvement in patients' quality of life may due to the improvements in pain intensity, stiffness, and physical functioning. However, since we did not conduct mediation analyses with these variables, we cannot confirm there is a clear relationship between improved quality of life and symptom relief and functional improvement.

Major strengths of our study are that the program of HBEI is highly generalizable, that it is simple to learn, and that it does not require any equipment, which facilitates learning and program adherence. Other strengths that ensured the study's quality and improved the reliability of the results were: (a) its rigorous training and assessment of the research staff, including the physiotherapists, research assistants, and the assessor; (b) its use of blinded assessments and data analyses; (c) its sample size; (d) the comparability of the groups at baseline; and (e) the high participant-retention rate and program adherence rate.
Our study also has some limitations. Although the study's hypotheses were not disclosed to the participants, they and the physiotherapists were not blinded to group allocation and were aware of the alternative treatment components. Therefore, the absence of blinding would likely have resulted in an overestimation of the effect of the exercise intervention. Due to limited resources, we did not conduct random assignment of participants to groups; nevertheless, the groups were comparable at baseline. We did not include patients with severe pain (NRS > 7) due to concerns about increasing their symptoms with exercise. Therefore, whether HBEI can reduce pain and improve other health outcomes of patients with severe pain remains to be confirmed. Finally, our intervention lasted only 12 weeks; so, we could not determine the long-term effects of the exercise intervention on the patients' long-term compliance or outcomes.

\section{Conclusions}

Our results showed that HBEI reduced pain intensity and joint stiffness, increased the muscle strength of the lower limbs, balance, and mobility, and improved the quality of life of elderly patients with KOA living in the community. The program is inexpensive, easy to use, safe, and suitable for being practiced at home. A long-term longitudinal study with randomized groups is needed to verify its long-term effects.

\section{Additional files} Additional file 1: Health Knowledge and Home Exercise Guide for KOA.
(DOC $19710 \mathrm{~kb}$ )

Additional file 2: Information on the patients enrolled in the study. This file includes the demographic characteristics and all outcomes of the patients enrolled in the study. (XLSX $43 \mathrm{~kb}$ )

Additional file 3: CONSORT 2010 checklist of information to include when reporting a randomized trial. (DOC $216 \mathrm{k}$

Additional file 4: The TIDieR (Template for Intervention Description and Replication) Checklist. (DOCX 29 kb)

\begin{abstract}
Abbreviations
6MWT: The six-minute walk test; AIMS2-SF: Arthritis Impact Measurement Scales 2 short form; BMI: Body mass index; CG: Control group; FTSST: The five-times-sit-to-stand test; GLM: General linear model; ICC: Intraclass correlation coefficient; IG: Intervention group; KOA: Knee osteoarthritis; NRS: Numeric rating scale; OA: Osteoarthritis; SD: Standard deviation; TUG: The timed up and go test; WOMAC: Western Ontario and McMaster Universities Osteoarthritis Index
\end{abstract}

\section{Acknowledgements}

We would like to thank Weishen Liu for helping organize and coordinate community interventions; Dr. Nan Li for his assistance with the statistical analysis; the native English speaking scientists of Elixigen Company (Huntington Beach, California) for editing our manuscript; and Dr. Yongchen Ma for editing our figure.

\section{Funding}

This research did not receive a specific grant from funding agencies in the public, commercial, or not-for-profit sectors. 


\section{Availability of data and materials}

The dataset supporting the conclusions of this article is included within the article (Additional file 2).

\section{Statement of CONSORT guidelines}

Our study adheres to CONSORT guidelines and includes a completed CONSORT checklist in Additional file 3 and a TIDieR checklist in Additional file 4.

\section{Authors' contributions}

$\mathrm{CH}$ participated in the design of the study, performed the data analysis, and drafted the manuscript. ZX and HH performed the assessment and exercise interventions for patients. LC collected and analyzed patient data. QW performed the statistical analyses. SS was a major contributor in the design of this study and revised the manuscript. All the authors read and approved the final manuscript.

\section{Ethics approval and consent to participate}

The study protocol was approved by the Peking University Medical Ethics Committee (IRB00001052-14058). All participants provided written informed consent.

\section{Consent for publication}

Not applicable.

\section{Competing interests}

The authors declare that they have no competing interests.

\section{Publisher's Note}

Springer Nature remains neutral with regard to jurisdictional claims in published maps and institutional affiliations.

\section{Author details}

'School of Nursing, Peking University, 38 Xueyuan Road, Haidian District, Beijing 100191, China. ${ }^{2}$ The Open University of China, 75 Fuxing Road, Haidian District, Beijing 100039, China. Institute of Sports Medicine, Peking University Third Hospital, 49 Huayuan North Road, Haidian District, Beijing 100191, China.

\section{Received: 6 September 2018 Accepted: 21 March 2019}

\section{Published online: 09 April 2019}

\section{References}

1. McAlindon TE, Bannuru RR, Sullivan MC, Arden NK, Berenbaum F, BiermaZeinstra SM, et al. OARSI guidelines for the non-surgical management of knee osteoarthritis. Osteoarthr Cartil. 2014;22:363-88.

2. Zhang Y, Jordan JM. Epidemiology of osteoarthritis. Clin Geriatr Med. 2010; 26:355-69.

3. Lawrence RC, Felson DT, Helmick CG, Arnold LM, Choi H, Deyo RA, et al. Estimates of the prevalence of arthritis and other rheumatic conditions in the United States. Part II. Arthritis Rheum. 2008:58:26-35.

4. Bennell $\mathrm{KL}$, Hinman RS. A review of the clinical evidence for exercise in osteoarthritis of the hip and knee. J Sci Med Sport. 2011;14:4-9.

5. Juhl C, Christensen R, Roos EM, Zhang W, Lund H. Impact of exercise type and dose on pain and disability in knee osteoarthritis: a systematic review and meta-regression analysis of randomized controlled trials. Arthritis Rheumatol. 2014;66:622-36.

6. Fransen M, McConnell S, Harmer AR, Van der Esch M, Simic M, Bennell KL. Exercise for osteoarthritis of the knee: a Cochrane systematic review. $\mathrm{Br}$ J Sports Med. 2015:49:1554-7.

7. Nelson AE, Allen KD, Golightly YM, Goode AP, Jordan JM. A systematic review of recommendations and guidelines for the management of osteoarthritis: the chronic osteoarthritis management initiative of the U.S. bone and joint initiative. Semin Arthritis Rheum. 2014;43:701-12.

8. Waller B, Munukka M, Rantalainen T, Lammentausta E, Nieminen MT Kiviranta I, et al. Effects of high intensity resistance aquatic training on body composition and walking speed in women with mild knee osteoarthritis: a 4-month RCT with 12-month follow-up. Osteoarthr Cartil. 2017;25:1238-46.

9. Ojoawo AO, Olaogun $\mathrm{MO}$, Hassan MA. Comparative effects of proprioceptive and isometric exercises on pain intensity and difficulty in patients with knee osteoarthritis: a randomised control study. Technol Health Care. 2016;24:853-63.
10. Oiestad BE, Osteras N, Frobell R, Grotle M, Brogger H, Risberg MA. Efficacy of strength and aerobic exercise on patient-reported outcomes and structural changes in patients with knee osteoarthritis: study protocol for a randomized controlled trial. BMC Musculoskelet Disord. 2013;14:266.

11. Segal NA, Williams GN, Davis MC, Wallace RB, Mikesky AE. Efficacy of blood flow-restricted, low-load resistance training in women with risk factors for symptomatic knee osteoarthritis. PM \& R. 2015;7:376-84.

12. Cho HY, Kim EH, Kim J, Yoon YW. Kinesio taping improves pain, range of motion, and proprioception in older patients with knee osteoarthritis: a randomized controlled trial. Am J Phys Med Rehabil. 2015;94:192-200.

13. McKnight PE, Kasle S, Going S, Villanueva I, Cornett M, Farr J, et al. A comparison of strength training, self-management, and the combination for early osteoarthritis of the knee. Arthritis Care Res (Hoboken). 2010;62:45-53.

14. Thomas KS, Muir KR, Doherty M, Jones AC, O'Reilly SC, Bassey EJ. Home based exercise programme for knee pain and knee osteoarthritis: randomised controlled trial. BMJ. 2002;325:752

15. Jorgensen PB, Bogh SB, Kierkegaard S, Sorensen H, Odgaard A, Soballe K, et al. The efficacy of early initiated, supervised, progressive resistance training compared to unsupervised, home-based exercise after unicompartmental knee arthroplasty: a single-blinded randomized controlled trial. Clin Rehabil. 2017;31:61-70

16. Ksibi I, Lebib S, Ben Salah FZ, Miri I, Koubaa S, Dziri C. The contribution of home based exercise programme in case of osteoarthritis of the knee. Tunis Med. 2008:86:881-9.

17. Carvalho NA, Bittar ST, Pinto FR, Ferreira M, Sitta RR. Manual for guided home exercises for osteoarthritis of the knee. Clinics. 2010:65:775-80.

18. Deyle GD, Allison SC, Matekel RL, Ryder MG, Stang JM, Gohdes DD, et al Physical therapy treatment effectiveness for osteoarthritis of the knee: a randomized comparison of supervised clinical exercise and manual therapy procedures versus a home exercise program. Phys Ther. 2005:85:1301-17.

19. Bruce-Brand RA, Walls RJ, Ong JC, Emerson BS, O'Byrne JM, Moyna NM. Effects of home-based resistance training and neuromuscular electrical stimulation in knee osteoarthritis: a randomized controlled trial. BMC Musculoskelet Disord. 2012:13:118.

20. Pfeiffer E. A short portable mental status questionnaire for the assessment of organic brain deficit in elderly patients. J Am Geriatr Soc. 1975:23:433-41.

21. Bellamy N, Buchanan WW, Goldsmith $\mathrm{CH}$, et al. Validation study of WOMAC: a health status instrument for measuring clinically important patient relevant outcomes to antirheumatic drug therapy in patients with osteoarthritis of the hip or knee. J Rheumatol. 1988;15:1833-40.

22. Xie F, Li SC, Goeree R, et al. Validation of Chinese Western Ontario and McMaster universities osteoarthritis index (WOMAC) in patients scheduled for total knee replacement. Qual Life Res. 2008:17:595-601.

23. Goldberg A. The five-times-sit-to-stand-test (FTSST), the short version of the activities-specific balance confidence (ABC) scale, and fear of falling predict step execution time (SET) in older adults. Arch Gerontol Geriatr. 2012;54:434-8.

24. Lang $C T$, King JC. The burden of maternal mortality and morbidity in the United States and worldwide. In: Preedy VR, Watson RR, editors. Handbook of disease burdens and quality of life measures. New York: Springer Science; 2010. p. 647-59.

25. Bennell K, Dobson F, Hinman R. Measures of physical performance assessments: self-paced walk test (SPWT), stair climb test (SCT), six-minute walk test (6MWT), chair stand test (CST), timed up \& go (TUG), sock test, lift and carry test (LCT), and Car task. Arthritis Care Res. 2011;63(Suppl 11):S350-70.

26. Guillemin F, Coste J, Pouchot J, et al. The AIMS2-SF: a short form of the arthritis impact measurement scales 2. French quality of life in rheumatology group. Arthritis Rheum. 1997:40:1267-74.

27. Zhu JL, Zhang YP, Pang LZ. Arthritis quality of life measurement scale 2 - reliability and validity of short volumes. Chin J Prev Control Chronic Dis. 2006;14:75-7.

28. Aglamiş B, Toraman NF, Yaman $\mathrm{H}$. Change of quality of life due to exercise training in knee osteoarthritis: SF-36 and WOMAC. J Back Musculoskelet Rehabil. 2009:22:43-5.

29. Barnett AG, Van DP, Dobson AJ. Regression to the mean: what it is and how to deal with it. Int J Epidemiol. 2005:34:215-20.

30. Escalante Y, Saavedra JM, Garcia-Hermoso A, Silva AJ, Barbosa TM. Physical exercise and reduction of pain in adults with lower limb osteoarthritis: a systematic review. J Back Musculoskelet Rehabil. 2010;23:175-86.

31. Association CO. Guide to the diagnosis and treatment of osteoarthritis (2007 edition). Chin J Joint Surg. 2007;1:254-6.

32. Rymore R. Arthritis in knee, oseoarthritis in knee. America: Imb Publishing: 2013. 
33. Parker D. Management of knee osteoarthritis in the yonger, active patient Berlin: Springer Berlin Heidelberg; 2016.

34. Veenhof C, Koke AJ, Dekker J, Oostendorp RA, Bijlsma JW, van Tulder MW, et al. Effectiveness of behavioral graded activity in patients with osteoarthritis of the hip and/or knee: a randomized clinical trial. Arthritis Rheum. 2006:55:925-34.

35. Nishimura A, Hasegawa M, Kato K, Yamada T, Uchida A, Sudo A. Risk factors for the incidence and progression of radiographic osteoarthritis of the knee among Japanese. Int Orthop. 2011;35:839-43.

36. Koca I, Boyaci A, Tutoglu A, Boyaci N, Ozkur A. The relationship between quadriceps thickness, radiological staging, and clinical parameters in knee osteoarthritis. J Phys Ther Sci. 2014;26:931-6.

37. Rasch A, Byström AH, Dalen N, Berg HE. Reduced muscle radiological density, cross-sectional area, and strength of major hip and knee muscles in 22 patients with hip osteoarthritis. Acta Orthop. 2007;78:505.

38. Peeler J, Christian M, Cooper J, Leiter J, MacDonald P. Managing knee osteoarthritis: the effects of body weight supported physical activity on joint pain, function, and thigh muscle strength. Clin I Sport Med. 2015;25:518-23.

39. Keskin D, Borman P, Ersoz M, Kurtaran A, Bodur H, Akyuz M. The risk factors related to falling in elderly females. Geriatr Nurs. 2008;29:58-63.

40. Kelsey UL, Berry SD, Procter-Gray E, Quach L, Nguyen US, Li W, et al. Indoor and outdoor falls in older adults are different: the maintenance of balance, independent living, intellect, and zest in the elderly of Boston study. J Am Geriatr Soc. 2010;58:2135-41.

41. Arnold CM, Gyurcsik NC. Risk factors for falls in older adults with lower extremity arthritis: a conceptual framework of current knowledge and future directions. Physiother Can. 2012;64:302-14.

42. Kabiri S, Halabchi F, Angoorani H, Yekaninejad S. Comparison of three modes of aerobic exercise combined with resistance training on the pain and function of patients with knee osteoarthritis: a randomized controlled trial. Phys Ther Sport. 2018;32:22-8.

43. Wang P, Yang L, Liu C, Wei X, Yang X, Zhou Y, et al. Effects of whole body vibration exercise associated with quadriceps resistance exercise on functioning and quality of life in patients with knee osteoarthritis: a randomized controlled trial. Clin Rehabil. 2016;30:1074-87.

44. Rat AC, Pouchot J, Fautrel B, Boumier P, Goupille P, Guillemin F. Factors associated with fatigue in early arthritis: results from a multicenter national French cohort study. Arthritis Care Res. 2012;64:1061-9.

45. Huang KH, Hsieh RL, Lee WC. Pain, physical function, and health in patients with knee osteoarthritis. Rehabil Nurs. 2017;42:235-41.

Ready to submit your research? Choose BMC and benefit from:

- fast, convenient online submission

- thorough peer review by experienced researchers in your field

- rapid publication on acceptance

- support for research data, including large and complex data types

- gold Open Access which fosters wider collaboration and increased citations

- maximum visibility for your research: over $100 \mathrm{M}$ website views per year

At BMC, research is always in progress.

Learn more biomedcentral.com/submissions 